\title{
Bion's Thinking on Psychotic and Non-psychotic Functioning Applied to Work with an Adolescent Psychotherapy Group
}

\author{
Dr Peter Slater \\ Senior Lecturer, and Programme Leader Child and Adolescent \\ PSYCHOTHERAPY, AUCKLAND UNIVERSITY OF TECHNOLOGY
}

\begin{abstract}
This paper explores Bion's thinking about the co-existence of psychotic and non-psychotic states in the personality. I contend that Bion's description of psychotic states, in particular, is highly relevant when applied to adolescent states of mind. The processes that emerged from an adolescent psychotherapy group are presented to provide an illustration of Bion's thinking and to reinforce the idea that such states are indeed present during the adolescent process. This work was undertaken in London, and the paper began its journey towards publication during the latter part of my work with this group and since my arrival here in Aotearoa New Zealand.
\end{abstract}

\section{Whakarāpopotonga}

E wherawhera ana tēnei pepa i te tirohanga a Bion ki te nohotahitanga o te mate rangirua me te kore-rangiruatanga mai o te āhua tuakiri. E tautohe ana au i te whakamāramatanga o te noho rangiruatanga, inarā, e tino hāngai ana inā whakatauhia ki te hinengaro o te taiohi. Ko ngā whakaputaranga i puta mai i ngā whakarōpūtanga kaiwhakaora hinengaro taiohi e whakatauhia ana hai whakaahua i ngā whakaaro o Bion, à, hai tautoko ake i te whakaaro e mau ana aua āhua i te wā tipuranga o te taiohi. I mahia tēnei mahi i Rānana, ka tīmata ake te haerenga o tēnei pepa kia tāia i te pito whakamutunga o taku mahi i te taha o tēnei rōpū,à, mai i taku taenga mai ki Aotearoa Niu Tīreni.

Keywords: adolescence; Bion; psychotic; non-psychotic; groups; curiosity; separateness; projective identification; introjection; transference

Slater, P. (2015). Bion's thinking on psychotic and non-psychotic functioning applied to work with an adolescent psychotherapy group. Ata: Journal of Psychotherapy Aotearoa New Zealand, 19(1), 49-65. DOI:10.9791/ajpanz.2015.05 (c) New Zealand Association of Psychotherapists Inc. 
The appetite for group work in public health services often appears to wax and wane. At times of high demands on services group work can be a useful resource in terms of reaching more clients within a single session. This suggests a rather disparaging view of the importance of group work but, unfortunately, is a fact of life when financial and other constraints are placed on mental health services despite the growth in demand for such services.

I begin with some thoughts about group life: Freud (1921) wrote: "and in the development of mankind as a whole ... love alone acts as a civilizing factor in the sense it brings a change from egoism to altruism" (p. 66). Later, Bion (1961) concurred with Freud in terms of the creative capacity of the group over and above the individual when he wrote of group life as being an opportunity to move from "narcissism to social-lism ... I consider that group mental life is essential to the full life of the individual, quite apart from any temporary or specific need, and that satisfaction of this need has to be sought through membership of a group" (p.160). He also wrote: "The whole point of looking at a group is that it changes the field of study to include phenomena that cannot be studied outside the group" (ibid., p. 24). More recently, Garland (2010) argued that: "The capacity to reflect before acting is the foundation stone of growth, development and creativity in both the small group and in society itself” (p. 4).

\section{An Adolescent Group}

The Building Relationships psychotherapeutic group took place within a National Health Service-funded, London-based, child and adolescent mental health service (CAMHS). The service had created an adolescent team to work with "hard to reach adolescents and their families" who often presented with complex, severe, and enduring mental health difficulties such as severe self-harming behaviours and suicidal ideation with strong intent. The emphasis was to provide intensive, community-based treatment programmes in order to prevent hospital or inpatient unit admissions. The Building Relationships group ran in conjunction with time-limited, goal-oriented groups offered by the service, for example, a Mood and Feelings Group and Dialectical Behavioural Therapy (DBT) groups.

The idea of offering group psychotherapy was initially met with enthusiasm as this resource had not been offered in a slow, open form before. This form of group work meant that individuals would enter and leave the group at different times while the group itself continued.

Referrals into this team were assessed on the basis of presenting features, including severe depression, often chronic self-harming behaviours, suicidal preoccupation, and risktaking behaviours above the norm for adolescent presentation. Psychotic and borderline features were prevalent, often accompanied by impairment in social functioning, inability to regulate emotional states, poor reflective capacity, and marked narcissistic means of object relating.

Many of the adolescents' histories included very poor early emotional experiences, often including trauma, abuse, deprivation, neglect, parental mental health issues, and parental drug and alcohol dependence. As co-facilitators of the group we felt it important, however, to include a variety of presentations within the group and for individuals with less complex presentations to also have access, where appropriate, to the group. This facilitated 
opportunities for those exhibiting more disturbed and worrying behaviour to have access and exposure to healthier, more resilient peers.

Naming the group Building Relationships both provided referral information for colleagues and identified the function of the group which was to explore and develop existing internal landscapes and the quality of external relationships, while examining the challenges and obstacles to such a process.

The explicit aims of the group took into consideration some of the key tasks associated with the adolescent process. We recognised that the developmental trajectory of many of the group had been severely curtailed and growth and development had become fraught with fear of any genuine process of separation-individuation (Mahler, 1974). In presenting this work in a different cultural milieu I recognise that adolescent developmental tasks may differ and be at odds with socio-centric cultures and societies.

The aims for the group were thought about in terms of improving self-awareness through exploration and developing an understanding of current ways of relating to others. Clearly the interplay between internal and external relationships was the major focus and it was envisaged that a group setting would lend itself to participants gaining insight into their internal landscape and its external manifestations. A movement from self-absorption and narcissistic need to one of genuine concern and consideration for the needs of the group was an intrinsic feature of this general focus upon relationships, along with a focus on the kinds of destructive impulses that heavily impinge upon forming and sustaining meaningful relationships with others.

Beginning to recognise the separateness of the individual, while developing an increased capacity to tolerate and manage separateness (rather than to overly fear or denigrate it), was felt to be a central aim for the group which was closely linked with an important task in the adolescent process. The facilitators recognised that this was quite a challenge for the adolescent and the group to grapple with. Garland (2010) acknowledged this:

To be a member of a group is to have to put into practice some ... earlier developmental steps to do with balance between love and hate; to be able to hold back on personal aims and ambitions when the needs of the group requires something else from its members. (p. 4)

\section{Outcome Measures}

All patients entering this child and adolescent mental health service were provided with questionnaires to record base-line measures of anxiety, depression, and pro-social capacities, such as the Strengths and Difficulties Questionnaire (Goodman, 1997) and Revised Children's Anxiety and Depression Scale (Chorpita \& Ebustani, 2014). These were followed up at three-monthly intervals.

On entering the group, the adolescents completed the Personal Relatedness Profile (Hobson, Patrick \& Valentine, 1998) which had been adapted for use with adolescents. This was followed up at three months and when an adolescent left the group. The authors suggested that the Personal Relatedness Profile questions scepticism about the reliability and validity of psychoanalytic judgments of patient-therapist transactions. 
It is possible to record reliable psychoanalytic judgements about qualities of interpersonal relatedness. Moreover, there is evidence that paranoid-schizoid and depressive position aspects of psychological functioning do constitute a meaningful constellation of clinically grounded phenomena. (Hobson, Patrick \& Valentine, 1998, p. 177)

This resource was seen as a means by which the facilitators could chart the nuanced shifts and developments in the quality of relating internally and therefore externally.

Despite initial enthusiasm from CAMHS staff for a psychotherapy group, referrals were slow in coming. Over time, however, a steady stream arrived and from disparateness a group began to form. This paper provides clinical vignettes from the numerous adolescent patients who entered and left this group at various points during its four-year process of becoming "internalised" by the service as a valuable treatment option.

\section{Adolescence and psychotic functioning}

"Fair Queen", quoth he "if any love you owe me, Measure my strangeness with my unripe years;

Before I know myself seek not to know me;

No fisher but the ungrown fry forbears;

The mellow plum doth fall, the green sticks fast, Or being early pluck'd is sour to taste.

(Shakespeare, 1953/2002, pp. 523-528)

Shakespeare's poem wonderfully captures the conflict and the demands facing the adolescent, who is caught betwixt the push toward the sensual and the tender and the pull back to the naïve, as yet unripened state of childhood. The adolescent process involves significant psychic upheaval and reorganisation. Developments in brain imaging have enhanced what we know of the brain and its considerable restructuring during this time of life:

There is a major process of pruning, the loss of grey matter and an increase in myelination the white wrapping around neurons leading to brain signals travelling 100 times faster. The adolescent brain becomes more efficient but less adaptive. (Music, 2011, p.188)

Such neuorobiological changes leave parts of the brain largely "off line", frontal lobe areas, in particular, which are linked to executive functioning and the capacity to analyse social situations. The limbic area, a more primitive part of the brain linked to risk taking and other behaviour fuelled and driven by emotion, is often functioning without the restraints of those prefrontal cortex areas during adolescence (Blakemore \& Choudrey, 2006).

Alongside such neurobiological reconfigurations, psychically the challenges of this process demand a reworking of primitive internal relationships, allowing for separation- 
individuation and some movement toward what we would call "an adult identity". The loosening and reworking of psychic structures during the adolescent process invariably evokes deep anxieties and conflict resulting from such internal changes.

Bion's (1967) idea of the psychotic part of the personality presented the mind as evacuating, via excessive splitting and projection, the information and sensations it receives. This part of the mind, he argued, co-exists with a non-psychotic part which retains contact with reality via the ego. The tension between different parts of the mind, often with one part taking dominance over the other, is a familiar portrait of the adolescent personality. Oscillations from dependence to attempted autonomy, rapid changes in object choice, political allegiance, musical taste, and an emphasis on outward appearance are often accompanied by a disavowal of the intolerable aspects of reality, arguably a reality that includes the prospect of growing psychic and physical separateness, and increased responsibility, expectation, and pressure emotionally, socially, and academically. During the conflict of normative adolescence, the psyche comes under extreme pressure to utilise paranoid schizoid functioning and can, therefore, be understood to operate increasingly in the psychotic part of the personality.

The fragility of such mental states and the rapidity of movement between different modes of functioning were viewed by Waddell (2006) as a major factor in the adolescent's unconscious return to a narcissistic state. She understood narcissism to be a developmentally appropriate defence in the face of such internal restructuring. Narcissistic functioning can promote health in the adolescent process by providing a form of object relationship, especially when the psyche is engaged in the struggle to separate. Through the projection of parts of the self into the surroundings, the adolescent creates a containing reciprocal object often in the form, interestingly, of a group or, in less benign circumstances, a gang.

The degree to which narcissism is turned to and the level of psychotic functioning is dependent on the early experiences of each individual. Group members often shared a common deficit in robust and benevolent internal objects, often a clear reflection of the deficit in early and current external environments and familial constellations. These often extremely detrimental early experiences are what delineated this clinical group from the non-clinical manifestation of the normative processes of adolescence.

\section{Psychotic and Non-psychotic Features Present in the Work of the Group}

Bion's (1961) observations of group dynamics drew forth the idea that the central task facing a therapeutic group was to find solutions to the problems of reality. He also suggested that the task of recognising and acknowledging such painful psychic and external realities evokes levels of anxiety that often prove difficult to contain within the group setting.

Placing emphasis on emotional experience as the foundation stone from which truth and therefore mental development can spring forth, Bion (1961) also considered the kinds of processes that can obstruct or negate development. His theory of thinking and the transformation of emotional experience also illustrated his idea of alpha functioning and the metabolising of unprocessed beta elements (proto-mental phenomena) into alpha elements, in other words, thoughts that can be tolerated and thought about. These ideas 
provided a background to the thinking about psychotic and non-psychotic processes which were frequently observed and thought about in the adolescent group; psychotic features that can attack and undermine the task of the group.

Bion's (1961) emphasis on "learning from experience" identified the key task for this group, which was for some to begin to develop and apply a reflective capacity to emotional experience as part of a broad attempt to search for truth and meaning. Fisher (2006) explored further the struggle involved in facing truthful aspects of one's emotional experience; the fear and anxiety which can terminate curiosity and a wish to learn and to think about:

Let's call the truth which is sought the answer ... One kind of answer aims at the pleasure of bringing the questioning to an end, the end of the need to seek to know, and in effect brings curiosity to an end. The other kind of answer keeps curiosity alive ... when the answer becomes a hypothesis, a preconception and expectation in a new quest. (pp.1-4)

Bion (1961) related such intolerance of the truthful nature of emotional experience to early primitive anxieties, anxieties central to Klein's (1946) description of the paranoid schizoid position. Bion (1967) focused upon the use of defences such as splitting and projective identification, which were very much anchored in Mrs Klein's (1946) nebulous realm of infantile phantasy life and, according to this perspective, are deployed in order to manage and alleviate anxiety of a persecutory nature. Bion developed this thinking from his earlier work on group processes and, in particular, his idea of "basic assumptions" that are present in group life. The basic assumptions of fight-flight, pairing, and dependency were thought by Bion to be in conflict with the purpose or central task of the group. For a therapeutic group this would be the process of self-examination and exploration. A group which was on task would therefore be consciously aware of its purpose and would recognise and tolerate separateness and difference. The basic assumptions often take the group away from its given purpose while determining how the group itself functions:

Work-group activity is obstructed, diverted, and on occasion assisted, by certain other mental activities that have in common the attribute of powerful emotional drives. These activities, at first sight chaotic, are given a certain cohesion if it is assumed that they spring from basic assumptions common to all the group. (Bion,1961, p.146)

Garland (2010) suggested that the idea that basic assumptions exist wherever there is a group mentality is central to Bion's (1961) thinking. Members of the group will unconsciously contribute to what Bion termed the "unanimous will of the group" (p.148). This places great pressure on group members to conform, often at the expense of individuality.

When considering characteristics observable in the development of schizophrenia, Bion (1967) identified a number of features which are used here as a helpful means of exploring and thinking about aspects of the clinical material arising from the adolescent group process. Examining aspects of the group in terms of psychotic and non-psychotic functioning allowed the facilitators to lend further meaning to the developmental tasks facing the adolescent. They also provided a framework for thinking about the modification of existing 
states of mind which currently impinge upon growth and development and movement towards a more genuine independent state of being. The following descriptions were used by Bion (1967) to identify four characteristic features of a personality where the psychotic aspect is in the ascendancy:

"A dread of imminent annihilation."

"A premature and precipitate formation of object relations."

"A hatred of reality, internal and external, which is extended to all that makes for an awareness of it."

"A preponderance of destructive impulses so great that even the impulse to love is suffused by them and turned into sadism." (p. 44)

Bion (1967) understood the psychotic part of the personality as operating in a paranoid schizoid mode of functioning. This area of the paranoid personality experiences a primitive anxiety arising from the death instinct which was felt as fear of annihilation. This fear is attached to an object, and translated into a fear of an "uncontrollable overpowering object" (Klein, 1946, p. 100). This visceral infantile anxiety had been observed in the group's interactions and behaviour around the group's first break which happened to coincide with Christmas. There were conversations concerning miscarriage, abortion, infantile loss, separation, and loss. These external experiences reflected the internal realities for most group members who, perhaps, had had inconsistent experiences of their own infantile states being accepted, looked-after, digested, and returned (beta to alpha functioning realised through parental reverie). The dread of annihilation takes the form of persecution, a stance familiar in the adolescent presentation as shown in the following vignette.

\section{Session 3}

Kate talks about feeling overwhelmed and persecuted by minor things. There is an increasing build-up in her speech and affect, she breaks down into a fit of loud sobs, tears streaming down her face. There is a sense of something very powerful in the room. Kate tries in vain to gather herself, apologises and says through her tears that she feels so embarrassed. Dayna says she knows how Kate feels, she was in a fight yesterday and only one person understood and they weren't there. Silence. Peter wonders about reactions from the rest of the group. Michaela says she feels like crying. Krishna speaks about finding school hard, how he feels he has lost the ground he made over the summer and is back to a position of feeling paranoid and concerned.

This vignette shows the group splintering under the pressure of shared emotional experience. Though the members all share aspects of a persecuting experience, both from their outside lives and within the group, they are unable to link their experiences together, forming an antiwork dynamic, which could be identified as Hinshelwood's (2012) "fragmented" container. The members were unable to come together to consider one person's experience (Kate's pain and embarrassment) and could only fall into their own, non-understandable, devastating, and preoccupying experiences which they direct at the facilitators. 
The infantile dread of annihilation is rooted in the physical sensations of bodily care, frustration, and satisfaction. The physicality so central to adolescence was often observed in the group through their actual bodily presence or indeed their physical absence from group sessions, in their state of dress, appearance, the keeping on of coats, scarves, and the keeping of bags on laps which had become a shared communication about people's states of mind. The clutching of large handbags to the torso or tightly buttoned coats restricting the visual range of the person bring to mind the infantile need for holding to reduce the risk for potential fragmentation and disintegration of the personality. The illness, which arguably each member holds and manifests for their family, strongly communicates the deficits in early life, and its accompanying nameless dread (Bion, 1962).

\section{“A premature and precipitate formation of object relations.” (Bion, 1967,p.44)}

Bion (1967) wrote of the conflict between the life and death instincts which in some instances is never decided. Although he was referring to such irresolvable internal states within the schizophrenic, I am suggesting that similarly intense, albeit less chronic, states can be observed as more natural developmental occurrences in the adolescent. In terms of life and death instincts, Bion is of course pointing to psychotic and non-psychotic states which exist simultaneously within the individual. The attack by psychotic elements of the personality on reflective thinking leaves the patient very dependent upon others to provide solutions and answers to many of their emotional difficulties. In the adolescent group this was illustrated by the quality of the transference material, in particular in relating to the cofacilitators as a parental couple. This transference could often be of a premature and tenacious nature. The co-facilitators were felt to be the ones in possession of all of the answers to the group members' difficulties:

\section{Session 8}

There is some light-hearted discussion and observation in the group about the gender-assigned roles of parents, what fathers do and don't do better than mothers and vice versa. We point out that beneath the humour in this discussion there is perhaps a more serious undertone which the humour may well be hiding. They could also be understood to be talking about parents falling short, parents who have disappointed and let them down, we could also be hearing of relationships with parents that are changing, parental figures that they are seeing in a different light now than when they were younger. Jodie says that she gets on better with her dad than her mum. Her eyes fill up with tears. Fighting these back she says that she has never really got on with her mother and that in the heat of an argument once she told her mother this. Jodie begins to cry openly now as she acknowledges that her words had really upset her mum.

After a moment or two and breaking thoughtful silence, Jodie suddenly asks Peter and Eva (co-facilitator) "Do either of you have children?" Eva demonstrates her curiosity about Jodie's question - how could we understand the question Jodie is asking. Jodie talks of her fantasy that psychotherapists must be "super parents" who 
would always get it right with their kids. Eva draws attention to Jodie's comments in a previous session about the facilitators being "mind readers" who are able at will to understand and meet her needs as if by magic.

Here the group appears to be struggling with the idea of the facilitators as a phantasised parental couple, perhaps wondering how we could both interchange from maternal functioning to a more paternal form of holding and protecting. This experience can be introjected as something of a positive experience or it can be enviously attacked and spoilt. There was little doubt that this experience sometimes put the group in touch with their feelings towards their own parental objects and posed the following central developmental tasks to be negotiated during this time:

- What do I do with feelings towards parental figures that evoke such strong feelings of love or hatred?

- How do I manage changing thoughts and feelings towards my parents?

- What kind of parent will I be?

The exploration of the counter transference of the facilitators highlighted our deep anxiety around the group falling apart, poor attendance, of the group ending abruptly, and wonderings as to whether we were doing a good enough job of providing cohesion for the group. This was mulled over and thought about in terms of us being the recipients of some of the group members' impoverished, deprived, and depriving internal states along with possible envy of our parental capacity to link and to think together and hold them in mind.

\section{"Hatred of reality, internal and external, which is extended to all that makes for an awareness of it.” (Bion, 1967,p. 44)}

As we have seen, hatred of reality is a key element in the psychotic part of the personality, disrupting the building blocks of the introjection of sensations, of meaning-making, and of linking, and, by extension, the possibility of thought and of thinking about. Bion (1967) used the concept of infantile sadistic attacks on the breast as an illustration of how reality can be minutely fragmented and projected. It is not only the object which is split in this attack, but the very part of the self that is aware of this hated reality, the reality of an object that has it all and spares very little. Ego and object are broken into fragments and evacuated, leaving the terrifying sense that neither the object nor the ego can ever be restored. The expulsion of parts of the self that are aware of reality disrupts primitive thought, preventing any movement towards a more integrated state that we know of as the depressive position. The expelled fragments are Bion's "bizarre objects" which cannot be joined, linked or taken in, experienced only as terrifyingly persecuting bits and pieces of meaningless experience.

\section{Session 63}

Mia, a 16 year old who engaged in severe, chronic self-harming behaviour, berates the group at every opportunity for its ignorance and intolerance of cultural, social, and 
sexual diversity, often silencing the group with her verbal onslaught.

Mia has remained silent for much of the session but follows up an interpretation from Eva by a vociferous attack on the "crap" that the facilitators talk and the white, middle class nature of psychoanalysis which she describes as "that Freud shit". The group fall silent, the silence is filled with feelings of deep anxiety, awkwardness, and anger. The facilitators after gathering themselves think together and with the whole group about the strong need to know, to have the conviction and the re-assurance that in our minds someone will fit into this category, or that, or the other. We were seeing how difficult it was to stay with the experience of actually not being sure about each other and indeed which camp, if any, people were occupying.

Mia was perhaps holding something very important for the group, which was the struggle to think about and articulate the issue of the differences between them. Perhaps Mia's need was to get rid of a judgmental, discriminating part of herself into the group, therefore leaving them with the feeling of ignorance, shame, and of not knowing. It seemed important for her to disavow this needy, not knowing part of herself, either through her castigation of the group or the self-harming that attempted time and again to damage and kill off this more vulnerable part. Surely an authentic place is where one engages in a struggle with one's own perhaps judgmental responses to difference and diversity, what Lowe (2014) described as a knowing about, rather than knowing as an acquisition of knowledge that obviates one's own prejudices and intolerances. What Bion (1967), Fisher (2006), and Lowe all highlighted is the great difficulty we can all share, and the ways in which we can evade, the difficult experience of getting to know something in a deep, emotionally real way. Bion reminded us of the cost of the kind of knowing that stultifies curiosity: "The disturbance of the impulse of curiosity on which all learning depends, and the denial of the mechanism by which it seeks expression, makes normal development impossible" (1967, p. 108).

Within the group, the reality of its multiple sibling situation was a perpetual feature. The denial of the reality of having to share the facilitators with other group members could be seen as an attack on the external reality of being in a group, and the internal reality as represented by ongoing oedipal tensions and resistances. The over-riding wish was for a more exclusive relationship.

Different members have all referred in the group to their individual meetings with the facilitators at points of crisis, quick to announce that last week during the individual session with Eva or Peter we spoke of this. On numerous occasions members have asked can they see one or both facilitators after the group and have waited behind to request prescriptions. On one occasion Kate waits until after the group have all left in order to give us details of her new blog, which she would like us to look at and review her art work, new recipes for cakes and decorative tips for fabric-work.

The internal struggles of the renewed oedipal challenge brought on by adolescence can be traced through these examples. External deficits have strongly flavoured internal landscapes and the histories of many members of the group suggest that they have not experienced the 
oedipal challenge in relation to a well-connected parental couple which can survive the child's efforts to attack the reality of their other-ness and together-ness. The countertransference communications such as those mentioned earlier are of note here, specifically the experience for Eva who after one such session discussed her anger and irritation at what she experienced as the group's dismissal and attack on my male identity when the group spoke about not liking or trusting men, then quickly adding: "But Peter, you don't count." I was the only man in the group at the time.

Group members initially denied the existence of other group members along with the possibility that the group process created a potential for dependence. The shifting numbers from week to week constantly reinforced the attack on any acknowledgement of group membership, of investment in the group, of commitment and attention to the main task of the group. Absences from the group were thought about in a number of ways, for example, as a reflection of impoverished internal states where absence from the group was a further deprivation of something potentially nourishing, increasing further the gap between the psychotic and non-psychotic parts of the personality. Alternatively, we asked ourselves whether absence was an expression of the adolescent's need to propel themselves away from the sense of a family that has both an external and internal basis. Perhaps here was evidence of Waddell's (2006) thinking about narcissism in adolescence when she wrote that it "...can be better understood precisely by examining not just its presentation but its purpose and function in the adolescent mind - a mind which is at once fluctuating, concrete, selfdeceiving and above all, turbulent in ways which at other stages of life, would be straightforwardly recognizable as clinically disturbed” (p. 26).

The denial of internal and external reality was a particular feature of the group when operating under basic assumptions, notably Basic Assumption Dependency (BAd) functioning (Bion, 1961). Bion described BAd as an unconscious phantasy whereby the group comes together to find safety and protection under the group leader, the leader being omniscient and filled with wisdom, enabling the group members to disavow themselves of their own valuable resources and capacities. The group fights against the disappointment of reality, that the leader does not have all the answers, but inevitably disappointment in the leader occurs and with it begins a search for a new leader.

The manifestation of this basic assumption in the group was illustrated by members failing to address each other; all conversation and interaction being with the group leader. There was little linking up and sharing with each other, instead talking only of their own, very different preoccupations and experiences. The rather prosaic quality of the interactions left the group at times in an impoverished state. It also placed significant emphasis on the facilitators to hold and carry the group, to make sense of things, and make links where the hatred of reality (that the group leaders did not have all of the answers) created an inability in the members to do so for themselves. Over the course of the group process this was experienced as an important stage whereby some group members would need to feel the safe, going on being nature of the facilitators' presence before being able to link more meaningfully with other group members.

Of note here are Hume's observations when describing a group where BAd is very much alive: 
...the unconscious phantasy is that the group has come together in order to find security and protection from one individual alone, usually the group leader. This individual is felt to be omniscient, possessing all the wisdom and solutions, while the other group members behave as if they know nothing and are devoid of resources and capacities. Though the group strives to defend itself against inevitable disappointment by holding tenaciously to its conviction, invariably the leader disappoints and the group turns to look for a new leader, destined to suffer the same fate. (2010, p.105)

Word came to the facilitators that the group were to be invited to a party hosted by Golan, a 17-year-old group member. Golan's precociousness was admired by the other group members; he was particularly articulate, intelligent, and open about his life and his conflict around his sexuality. The party went ahead despite recommendations from the facilitators that this could undermine the task of the group. During the following sessions there was opportunity for the facilitators to think with the group about this event. Thought was given to the possible denial and denigration of the reality of the psychotherapeutic space which was put aside for thinking (flight towards mindlessness in contrast to something more mind-ful), often about difficult and painful aspects of emotional experience. Also being annihilated, we wondered, were the boundaries around the time the group met; a rebellious coup on the part of the adolescents against strict parental controls of when and where we meet. Away from the group, we thought of the need of the adolescent to challenge parental figures, to push at boundaries, often out of a hope that the container is both flexible and that it does indeed exist.

\section{"A preponderance of destructive impulses so great that even the impulse to love is suffused by them and turned into sadism." (Bion,1967,p.44)}

Bion (1967) developed Klein's (1946) earlier theory involving sadistic attacks on the breast and the heavy deployment of such mechanisms as splitting and projective identification. The sadistic attacks are born out of hatred of the awareness of internal and external reality. According to Klein, if there is a preponderance of hatred then the process of taking in a good, benevolent object fails. This has direct implications for the therapeutic process. Bion took this up in terms of the psychotic part of the personality whose sadistic attacks set about destroying links between sense impressions and consciousness, in other words the capacity to think about, to reason, and to digest experience through the use of memory, judgment, and thought.

In relation to this inability to feed or digest experience, we noticed that the group members who exhibited the most disturbed and worrying states of mind were those who seemed preoccupied with thoughts and conversations about the junk food they fed themselves. It seemed that this kind of feeding of the self was familiar and decidedly more palatable than the kind of food for thought that group psychotherapy offered.

Self harming behaviour and suicidal ideation, often laden with intent, was a common presentation of many group members. Bell's (2010) formulation of "who is killing whom" (p.45) is relevant to Bion's (1967) ideas of sadistic attacks on linking; sadistic attacks against 
an object that is felt to be withholding or, conversely, overwhelming. Absence from group sessions could be infused with hostility and a sense of such withholding, often following a session where the adolescent had heavily invested something of themselves in the group. Bion's thinking about excessive splitting and projective identification was helpful in lending meaning to these ongoing absences: the absent group member leaving behind unwanted aspects of the self for the group to hold and to manage. What was also striking for the facilitators, as noted earlier, was the enormous sense of impoverishment and deprivation which such excessive exporting of aspects of the self could engender. We were able to think about this in terms of members leaving us with a communication of the deprivation and despair experienced in their lives. Bion had been one of the first to think about projective identification as a primitive means of communication of such unprocessed, un-metabolised experience.

Perhaps due to such excessive splitting and projective identification, the sense was that for a number of the adolescent patients, the group could not be held onto in their minds as something good, helpful, nourishing - keeping something good alive seemed almost impossible at times.

Kate had been attending the group regularly and after her initial struggles had been able to describe her ongoing issues with friends at school and an incredibly difficult relationship with her father. Kate's words often poured out of her, filled with simmering resentment and grievance. It was apparent that it was incredibly difficult to take anything from the group that would help her to process things. During the Christmas break and on Christmas Eve itself, Kate took a considerable overdose following a family argument. Her family stayed with her at A\&E until zam Christmas morning when she was finally discharged home.

Having missed a number of sessions following the group's return from the break, on her own return Kate spoke of being overwhelmed by feelings, angry, hateful, bitter feelings, towards almost everyone, but her father in particular who she felt did not care about her, and who she felt had not made any effort to try to understand how she felt.

What had made it difficult to return earlier to think about what had happened, to think about these very painful feelings? Kate, echoing a number of the other group members' experiences, said she had actually forgotten about the group, she had no energy, did not want to think about bad things, instead had turned her attention to her embroidery, cake making, and photography as a means of escaping painful feelings. The group explored Kate's possible angry feelings towards the perceived parental figures in the group letting her down, not being there over the break, and not making any effort to understand her needs perhaps when she most needed someone or something to be there. A useful discussion ensued about how difficult it was to depend on something that might not always be there. Michaela spoke of how she tried not to depend on anyone if she could help it, especially not boyfriends. It was put to the group that it was perhaps easier at times to leave unwanted thoughts and feelings with the group, which could make coming back to the group all the more difficult. 
Kate appeared to attack her awareness of separateness as well as the more needy, dependent part of herself. If she obliterated her awareness of her need for the other, then she did not have to have the experience of being separate. The intense struggle of recognising the otherness of the other is at very heart of the matter.

\section{Brief Discussion and Analysis of Outcome Measures}

At the time of writing, 45 young people had been assessed and went on to become members of this psychotherapy group. Predictably, given the client group, a proportion did not engage in this process for long enough to allow any visibly mutative processes to occur. For most however, the outcomes of this treatment proved interesting. To date, five who had been discharged from the service were re-referred for further input from the clinic at a later date, and all of them requested individual child and adolescent psychotherapy. Four have left the group and are, so far, successfully managing the transition to university. Four continued with group psychotherapy after the author left the service.

A follow-up review was undertaken of those who left the group and the service after a sixmonth interval. Twelve ex-group members responded to this, with eight reporting continuing progress and improvements in emotional states. These self-reports coincided with results from the Strengths and Difficulties Questionnaire and Revised Children's Anxiety and Depression Scale, and four reported declines in mood around times of transition and crisis within families. All confirmed that they would seek further help and support if necessary.

The Personal Relatedness Profile showed that for a significant number of those who had entered group psychotherapy there was an overall decrease in levels of paranoid schizoid functioning, while depressive position functioning increased on average by $30-40 \%$.

Perhaps more importantly, but not surprisingly given the analysis of data recorded above, self-harming behaviours and suicidal intent lessened for most of those involved in this psychoanalytic psychotherapy group, and only one person of the 45 needed an inpatient admission during the four years the group ran. I am aware that measuring well-being is a complex process and entails many variables but am offering these figures as food for thought. For me the most important evidence came from the experience of a patient I shall call Gina. Gina was our longest member ( 18 months) and had joined the group following years of self-mutilation and a number of serious suicide attempts that had left her hospitalised for several weeks at a time:

I know I'm a very different person now, but don't make me explain why or how I feel better for coming here, I'm not sure I'm ready to think about that yet. I'm just happy feeling better and I'll leave it at that.

Gina is now studying psychology at university. 


\title{
Concluding Thoughts
}

As I record my thoughts about this group, it is pleasing, gratifying, and very painful to think that while I create a life on the other side of the world, the group continues to go on being. Putting the brakes on one's own narcissism and omniscience is a challenge. I am put in mind of the elusive nature of Bion's (1961) concept of $\mathrm{K}$ and the struggle for meaning, knowledge, and understanding that merely poses another question, or indeed another challenge.

I will leave the courageous reader with a penultimate vignette which comes from one of my last sessions with the group.

\begin{abstract}
Session 178
Golan said he often wondered what it would be like to sit in Molly's seat on the other side of the room. "Dare I risk leaving my chair," Golan asked, laughing anxiously and more to himself it seemed than to the group. The group urged Golan on, saying they too would like to see what it would be like sitting in another seat. Roberta was the first to stand and this precipitated others to move about and exchange seats. There was nervousness in their laughter and quickly Golan said no he preferred his own seat and raced back to his own chair. Others pointed to the benefits the original occupants had in their seating placements. As soon as all were back in their original seats the talk quickly moved on to food and what foods each would have that evening and which food they preferred.
\end{abstract}

It was as if in changing seats the group were allowing themselves tentatively to see things from the other's perspective, a different point of view, what might it be like to be in someone else's shoes? This poses them an existential question of sorts: "Can I truly understand what others are thinking and perhaps feeling?" This puts one in touch with the very nature of the work. On this occasion it proved too difficult to sustain this idea and they retreated to something more akin to self-feeding and self-soothing. The truth here is experienced as having a foot in the world of the other. The starvation of such truth is analogous to physical starvation. The opportunity to find truth in one's own emotional experience is what the group attempted to provide a space for.

Rustin (2013) talked of the need for the therapist to hold onto the hope that the suffering and struggling patient entrusts us with. Williams, Williams, Desmarais, and Ravenscroft (2004) also spoke of our need to generously accept all that the patient entrusts us with. To keep ourselves from what Bunyan (1965) in Pilgrim's Progress laments as the slough of despond is the fundamental challenge of the child and adolescent psychotherapist. When working with such complex, severe, and enduring disturbance it is to do so willingly which I suggest is, for the child or adolescent, the beginning of something more hopeful.

Within the group there were moments of genuine concern for the despair of each other, when one's own pain and preoccupation was put aside for an instant, which brings us back to Freud's (1921) thoughts on the shift from egoism to altruism and Bion's (1961) assertion that group mental life satisfies a universal need. 
Kristen says she often wonders how the facilitators feel at the end of the group sessions. Do we go away feeling worse than when we came in like some members of the group do?

This was indicative of the subtle and often imperceptible change that occurred for many group members who managed to engage in such a difficult and challenging process. Bion I am sure would argue that for true learning and development to occur it could not be any other way.

\section{References}

Bell, D. (2010). Who is killing what or whom: Some notes of the internal phenomenology of suicide. In S. Briggs, A. Lemma, \& W. Crouch (Eds.), Relating to self-harm and suicide: Psychoanalytic perspectives on practice, theory and prevention (pp. 45-61). London, UK: Routledge.

Bion, W. R. (1961). Experiences in groups. London, UK: Routledge.

Bion, W. R. (1962). Learning from experience. London, UK: Karnac.

Bion, W. R. (1967). Second thoughts. London, UK: Karnac.

Blakemore, S. J., \& Choudry, S. (2006). Development of the adolescent brain: Implications for executive function and social cognition. Journal of Child Psychology and Psychiatry, 47(3-4), 296-312. doi: 10.1111/j.1469-7610.2006.01611.x

Bunyan, J. (1965). Pilgrim's progress. Harmondsworth, UK: Penguin

Chorpita, B. F., \& Ebustani, C. (2014). Revised children's anxiety and depression scale. Retrieved from www.childfirst.ucla.edu/Resources.html

Fisher, J. V. (2006). The emotional experience of K. International Journal of Psychoanalysis 87 , 121-37. doi: 10.1516/5DY5-9PWV-EToR-2Y1R

Freud, S. (1921). Group psychology and the analysis of the ego. In J. Strachey (Ed. \& Trans.), The standard edition of the complete psychological works of Sigmund Freud, (Vol.18, pp. 65-144). London, UK: Hogarth Press.

Garland, C. (2010). Introduction: Groups and groupings. In C. Garland (Ed.), The groups book: Psychoanalytic group therapy, principles and practice (pp.1-14). London, UK: Karnac.

Goodman, R. (1997). Strengths and Difficulties Questionnaire: A research note. Journal of Child Psychology and Psychiatry, 35, 1483-1494. doi: 10.1111/j.1469-7610.1997.tbo1545.x

Hinshelwood, R. D. (2007). Bion and Foulkes: The group as a whole. Group Analysis, 40(3), 344356. doi: $10.1177 / 0533316407076115$

Hinshelwood, R. D. (2012). Links and perpectives on the individual and the group. The Psychoanalytic Quarterly, 81(3), 589-600.

Hobson, P., Patrick, M., \& Valentine, J. D. (1998). Objectivity in psychoanalytic judgements. British Journal of Psychiatry, 173, 172-177.doi: 10.1192/bjp.173.2.172

Hume, F. (2010). Bion and group psychotherapy. In C. Garland (Ed.), The groups book: Psychoanalytic group therapy, principles and practice (pp.101-129). London, UK: Karnac.

Klein, M. (1946). Notes on some schizoid mechanisms. International Psychoanalysis, 27, 99-110.

Lowe, F. (2014). Thinking space: Promoting thinking about race, culture and diversity in psychotherapy and beyond. London, UK: Karnac. 
Mahler, M. (1974). Symbiosis and individuation: The psychological birth of the human infant. Psychoanalytic Study of the Child 29, 89-106.

Music, G. (2011). Nurturing natures, attachment and children's emotional, sociocultural and brain development. London, UK: Psychology Press.

Rustin, M. (2013). Rigidity and stability in the psychotic patient. In D. Bell, \& A. Novakovic, (Eds.), Living on the border (pp. 28-44). London, UK: Karnac.

Shakespeare, W. (2002). Venus \& Adonis. In C. Burrow (Ed.), The Oxford Shakespeare: The complete sonnets and poems. Oxford, UK: Oxford University Press. (Original work published 1953.)

Waddell, M. (2006). Narcissism: An adolescent disorder? Journal of Child Psychotherapy, 32(1), 21-34. doi: $10.1080 / 00754170600563703$

Williams, G., Williams, P., Desmarais, J., \& Ravenscroft, K. (2004). Introduction. In G. Williams, P. Williams, J. Desmarais, \& K. Ravenscroft (Eds.), Exploring eating disorders in adolescents: The generosity of acceptance (Vol. 2, pp. xiii-xxiv). London, UK: Karnac.

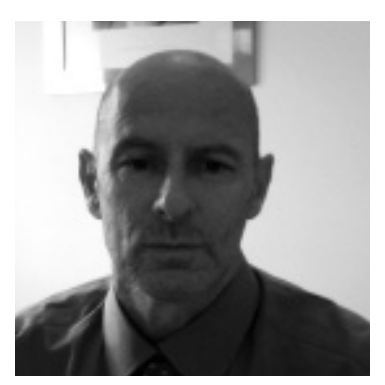

Dr Peter Slater is a Senior Lecturer and the Programme Leader of the Child and Adolescent Psychotherapy programme(s) at Auckland University of Technology. He works in private practice in Auckland as both a child and adolescent psychotherapist and as an adult psychotherapist. Peter has previously worked as Principal Child and Adolescent Psychotherapist and as Clinical Team Leader at Child and Adolescent Mental Health Services in London and Kent. He has been a Visiting Lecturer at the Tavistock Clinic where he undertook his training and at the Anna Freud Centre in London. Contact at: peter.slater@ aut.ac.nz . 